\title{
Ableism in the medical profession
}

\author{
Cite as: CMAJ 2020 April 14;192:E411-2. doi: 10.1503/cmaj.191597
}

CMAJ Podcasts: author interview at https://soundcloud.com/cmajpodcasts/191597-medsoc

D he term "ableism" can be defined as practices or policies that treat people with disabilities as if they were invisible, disposable and less than human, while taking for granted ablebodiedness as humanity's default state. ${ }^{1}$ Ableism is a force I have had to negotiate and resist all my life, even though I wasn't fully aware of it as a form of oppression until I entered a PhD program in English and Cultural Studies at McMaster University at age 39. There, I completed a dissertation on the representations of somatic pain within settler- and Indigenous-authored fictional texts. ${ }^{2}$ Guiding my thinking while I wrote the dissertation was not only an archive of biomedical sources that included Ronald Melzack, ${ }^{3}$ a name I knew from my training as a medical doctor almost 2 decades earlier, but also giants in the field of disability studies like Lennard Davis, ${ }^{4}$ Petra Kuppers ${ }^{5}$ and Tobin Seibers. ${ }^{6}$ After investing in this new learning, I capitalized on a lifetime of exclusion and derision and became politically active seemingly overnight, engaging in a host of activities designed to promote and assist the fates of my people, the mentally ill.

I did not expect to be able to promote this kind of activism within medicine itself, but early in 2019, I was asked to participate on a panel organized by the Ontario Medical Association's Physician Health Program (PHP), the professional body that is responsible for the welfare of ill and addicted physicians.

Being asked to participate made me reflect on my own lived experience as a chronically ill person. Two large points seemed irresistible to bring to a medical audience: I wished to sketch different systems of knowledge, biomedicine and disability studies; and I wanted to talk about how biomedicine is poorly serving not only disabled people, but also disabled physicians.

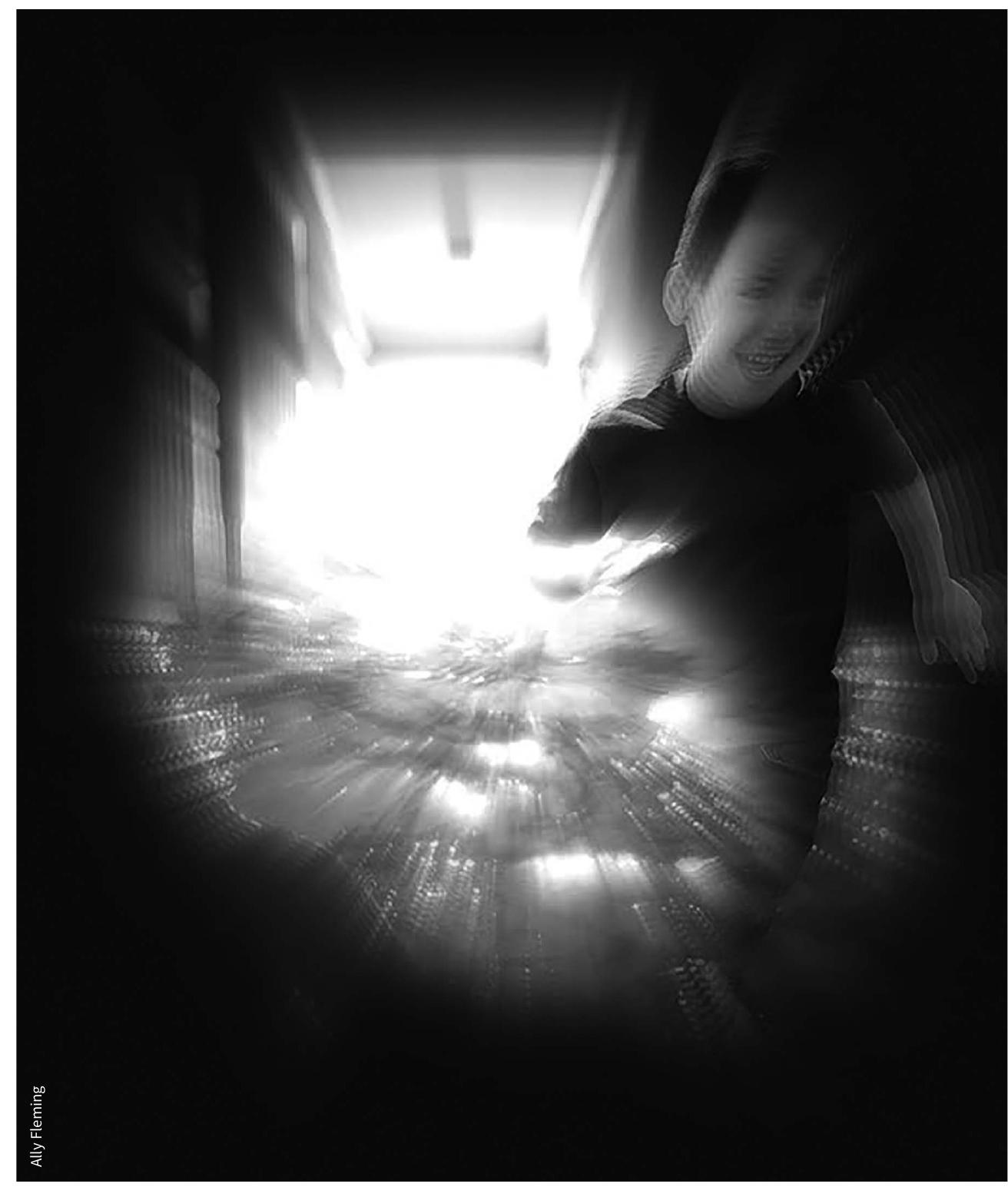

Medicine is, at bottom, a discipline that thinks pathologically. According to a velocity of knowledge that has exponentially increased since the 18th century via scientific experimentation and technological advance, medicine functions according to the basic idea that "healthy" is "normal" and "unhealthy" is "abnormal." The information medicine vends as truth is predicated on this distinction. In a recent piece in CMAJ, Heidi L. Janz writes that disabled people "remain subjected to ableist attitudes in many sectors, including - often especially - the health care 
system." The reason, as Janz correctly identifies, is based in medicine's presumption that "not normal" is the same as "unhealthy." I wish to include ill physicians in Janz's formulation, for the same oppressive forces medicine wields against its subjects, it also wields against itself.

In medical school, I experienced the distinction personally: I was mad, but desperately trying to pass. I can recall staying in a bed for days, becoming vertical only to use the bathroom, and then, after such down periods, working furiously to catch up with other students - all because I wanted to be a good doctor. Despite the intense bursts of work, I received the predictable feedback applied to a student looking and sounding like me in that era in which the rise of professionalism meant that I was characterized as bad, a problem student. Not one who was, constantly, thinking I should die, that I should do as the world, as the profession, seemed to want. I even did my unwitting best to be recognized as bad because it was somehow better to be dysfunctional than sick.

Faculty otherwise inclined to treat illness in people dealt with me accordingly, and under the sign of "unprofessional behaviour" I was assigned remedial activities that put additional strain on my health. But I preferred those to acknowledging - as per the paradox - something I didn't understand myself, and for which I couldn't give voice, having no words to do so other than words provided to me as part of a training process designed to diagnose others. I knew, somehow, that I was, indeed, a bad medical learner, an unprofessional student who could never meet the expectation of perfect health in medical culture. I knew this inside, though I didn't have words for that knowledge; and I was confused, because I also felt this knowledge as proof of unsuitability, of badness. Though I rejected the prospect of being a good biomedical drone because I couldn't be one, I also felt the dissonance of not being able to be one.

As Delese Wear and Julie Aultman write in their Introduction to Professionalism in Medicine: Critical Perspectives, professionalism has been uncritically "accepted as an absolute good" which falls under the "steering mechanism" of "assessment" that results in a flattening of the "richness, complexity, and contradictions of professionalism in medicine." For anyone with an invisible disability such as mental illness, the consequences are obvious: "every individual is made acutely aware that [his] conduct and performance is under constant scrutiny." ${ }^{8}$ But what of those with an innate skepticism of institutional power and norms based on their lived experience of oppression? How could professional norms change for the mentally ill to prevent that harmful narrowing described by Wear and Aultman? Physicians implicitly experience revulsion at illness among their colleagues because they are trained to see abnormal as unhealthy. Yet, according to professional ethics, physicians are supposed to offer their very best to patients, which is just another one of perfectionism's toxic varieties. It's a perfect storm of norms.

In solidarity with that self of more than 20 years ago, I sketched the above story in as nonlinear a fashion as possible to the PHP audience. I tried to convey the bind my 21-year-old self was in, acutely ill and encouraged to think of myself as bad by medicine, while society and its default ableism - the daily, small reminders from friends, family and strangers that I didn't talk normal, look normal, act normal - had already provided the basic program long before. Looking out at them, I felt as if I had jumped off a building late one night in the South End of Halifax to say to medicine, and to society, "We must all take care with one another; we all have so little time together."

As it happens, burnout was the topic $d u$ jour for the PHP. If we are to consider the category of burnout (a new member in the family of mental illness), shouldn't scholars of disability studies contribute to the formulation? The medical literature is beginning to include articles and accounts of disability within the profession, like those by Laura Bulk and colleagues ${ }^{9}$ and Neera Jain, ${ }^{10}$ but as of yet no one seems to have taken on the idea that the present crisis of burnout within medicine has something to do with a toxic culture of professional surveillance. Scholars of disability studies could do this.

To the audience of fellow physicians, I said, "I have always been 'ill.' And this is, to me, 'normal.' There is no origin story to be found, or overcoming narrative I have to provide." I asked, "What can you do to address this problem? I address it every day by subsisting in the clinic, but also through a host of activist organizing designed to improve the plight of my people, the mentally ill."

And so I ask you, too, reader: What can you do? If I could make 2 recommendations, the first would be that change starts at home: be kind to a suffering physician today. We're surrounded by them. The second is to consider that disability is a productive status, not something to be dismissed as merely pathological. Even the heartiest and most hale among us are able-bodyminded only temporarily, and as such, we live on a continuum. If medicine were to understand the independence of disability as a state of being, distinct from categories of normal and pathological, then perhaps the profession could heal from its self-injurious tendencies.

\section{Shane Neilson MD PhD}

Department of Family Medicine, Waterloo Regional Campus, McMaster University, Kitchener, Ont.

\section{References}

1. Dolmage J. Disability rhetoric. 1st ed. Syracuse (NY): Syracuse University Press; 2014.

2. Neilson S. Companions in this age: a study of pain in Canadian literature [dissertation]. Hamilton: McMaster University; 2018.

3. Melzack R. From the gate to the neuromatrix. Pain 1999;82:S121-6.

4. Davis LJ. Enforcing normalcy: disability, deafness, and the body. New York: Verso; 1995.

5. Kuppers P. Towards a rhizomatic model of disability: poetry, performance, and touch. J Lit Cult Disabil Stud 2009;3:221-40.

6. Metzl JM, Kirkland A, eds. In the name of pain. In: Against health: how health became the new morality. New York: New York Press; 2015:183-94.

7. Janz HL. Ableism: the undiagnosed malady afflicting medicine. CMAJ 2019;191:E478-9.

8. Wear D, Aultman J. Professionalism in medicine: critical perspectives. New York: Springer; 2006.

9. Bulk LY, Easterbrook A, Roberts E, et al. 'We are not anything alike': marginalization of health professionals with disabilities. Disabil Soc 2017;32:615-34.

10. Jain NR. Political disclosure: resisting ableism in medical education. Disabil Soc 2019 Aug. 9 [online]. doi:10.1080/09687599.2019.1647149.

This article has been peer reviewed.

Funding: Shane Neilson is supported by a Talent Grant from the Social Sciences and Humanities Research Council of Canada.

Shane Neilson is poetry advisor for CMAJ and was not involved in the editorial decisionmaking for this article.

Competing interests: None declared. 